\title{
IDENTIDADE,
}

\section{ESTEREÓTIPOS E POLÍTICAS}

\section{O CASO DOS ROM NA ITÁLIA}

\author{
Nando Sigona * \\ (Tradução do italiano por Helion Póvoa Neto)
}

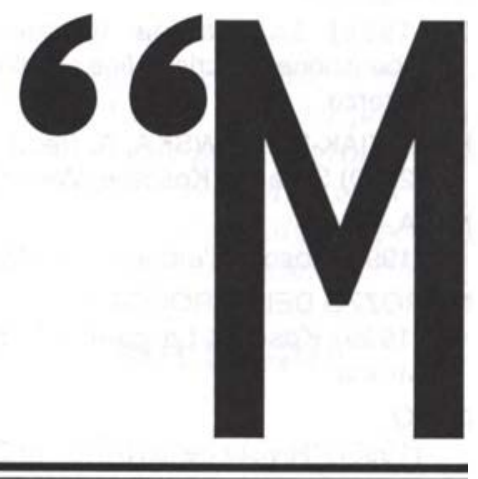

uitos motivos me levaram a mudar de vida: em primeiro lugar, o fato de ser 'nômade', ou seja, de rom tornar-me 'nômade', tornar-me 'cigano', com todos os preconceitos, sobretudo negativos, que isto comporta. Quando estava em meu país, nunca tinha pensado em mim mesmo como um 'nômade'. Não pensava em mim mesmo como um 'cigano': sujo, maltrapilho, ladrão. Por isso, quando cheguei na Itália, decidi trabalhar ativamente pelos direitos dos rom. Quero mostrar aos italianos que nenhum 'cigano' chamaria de 'cigano' um outro rom".' (D. M., rom macedônio)

Como as políticas contribuem para a reprodução e consolidação dos estereótipos? Como, por sua vez, os estereótipos tornam-se fatores de legitimação para as próprias políticas? Como, ainda, ambos influenciam a identidade dos indivíduos e dos grupos que pretendem explicar e governar? Este artigo explora tais interrogações, em particular quanto ao caso dos rom na Itália, enfocando como o discurso público sobre "ciganos" e "nômades", alimentado por estereótipos e preconceitos antigos e novos, tornou-se a base para políticas sociais discriminatórias que permitiram a manutenção de um estado de pobreza e segregação, favorecendo por vezes diretamente a marginalização das comunidades rom. Como destaca Piasere $(2004,4)$, “a categoria 'cigano' parece portanto uma identidade externa, a ser desconstruída e depois reconstruída englobando-se diversos movimentos rom; esta construção 'externa' deve ser um ponto de partida já que, devido a ela, os rom compartilharam destinos análogos na Europa."

A presente intervenção enfoca tais processos e indaga como políticas sociais e estereótipos contribuíram, conjuntamente, para a construção daquelas identidades burocráticas utilizadas pelo sistema político para fins de governo e controle. Mas há ainda uma outra face da moeda. Retomando uma frase de Zetter $(1991,40)$, o artigo questiona "como a identidade se forma, se transforma e é manipulada dentro do contexto definido pelas políticas públicas e, sobretudo, pelas práticas burocráticas".

As definições oficiais não apenas contribuem ativamente para as definições de identidades coletivas como também, sendo instrumentos do sistema político, tornam-se expressão e síntese de sua própria estrutura, proporcionando um quadro da dialética e dos conflitos internos entre atores institucionais e não institucionais. As definições não são monolíticas. Elas exprimem aquela que é, segundo Foucault, a própria condição de possibilidade do poder, "a base móvel de relações de força que definem sem parar, por sua disparidade, situações de poder, mas sempre locais e instáveis" (Foucault 1988, 82). As definições podem, assim, estar em conflito entre si e, conseqüentemente, produzir resultados conflitantes, tanto do ponto de vista 
conceitual quanto político.

O caso dos rom na Itália presta-se bem à observação de tais processos. Como se verá em seguida, o tão contestado quanto difundido uso do termo "nômade" para indicar o conjunto de grupos rom e sinti $i^{2}$ é um exemplo relevante tanto das ligações entre categorias burocráticas, políticas públicas e identidades dos sujeitos, quanto da fluidez e do caráter circunstancial do poder e de suas manifestações concretas (Sigona, 2002; 2003).

\section{O CONTEXTO}

O heterônimo "ciganos", bem como sua versão politicamente correta "nômades", são categorias de classificação complexa ${ }^{4}$, constituídas por elementos assemelhados mas bastante diversos (Piasere, 1995). Referem-se a e incorporam um conjunto de grupos e subgrupos relacionados entre si segundo diversos modos. Dentre eles, três são os componentes principais: os rom, os sinti e os caminhantes. Uma outra distinção, que assume como divisor de águas a categoria da cidadania, se pode fazer entre cidadãos italianos e cidadãos estrangeiros (e, entre estes, um importante componente aparece como subcategoria: os refugiados políticos).

A Itália, entre os membros da União Européia, é o único país em que o número de rom estabelecidos depois de 1945 equipara, se não supera, a população rom e sinti anteriormente estabelecida. Os rom e sinti italianos surgiram no território do país desde o século XV. Os sinti alcançaram o Centro-Norte da Itália atravessando por terra os Balcãs. Os rom atravessaram o mar Adriático e estabeleceram-se ao Sul, (Karpati, 1969; Karpati, 1993). Quanto aos caminhantes, sua origem não é clara. Muitos entendem tratar-se de um grupo autóctone gradualmente separado do resto da sociedade ao longo dos séculos (Soravia, 1981; Sidoti, 2003; Piasere, 2004). Rom e sinti são divididos numa pletora de subgrupos e clãs familiares que freqüentemente assumem o nome da região em que se encontram estabelecidos ou da atividade econômica predominante desenvolvida pelo grupo (Viaggio, 1997).
$\mathrm{Na}$ ausência de estatísticas oficiais sobre a população rom e sinti na Itália, recorre-se a estimativas, segundo as quais existem no momento cerca de 120 a 150 mil rom, sinti e caminhantes residentes no país, dos quais cerca de $60 \%$ são cidadãos italianos. $\mathrm{O}$ estilo de vida itinerante, o nomadismo, é hoje residual, envolvendo sobretudo grupos sinti. A maioria dos demais $40 \%$ de rom e sinti chegaram à Itália em tempos recentes, principalmente da península balcânica e da Romênia. Estes grupos tendem a se autodefinir como "rom".

Entre os rom chegados recentemente à Itália, um grupo importante é constituído por refugiados de guerra, freqüentemente desprovidos de documentos válidos de residência. Seus vistos concedidos por motivos humanitários estão já vencidos ou são de difícil renovação ou conversão em autorizações para trabalho (Schiavone, 1997).

Cerca de um terço da população rom e sinti residente na Itália habita em campos, os assim chamados "campos nômades", isolados do resto da população. Parte destes campos são abusivos, parte são reconhecidos pelas administrações locais, parte foram construídos por estas administrações (Brunello, 1996). Conforme denúncia da Comissão Européia contra o Racismo e a Intolerância (ECRI, 2002), "a situação de segregação física dos rom e sinti na Itália parece refletir um tipo de abordagem por parte das autoridades italianas baseada na consideração de que os rom são nômades e portanto querem viver em campos". Do mesmo modo, a Comissão das Nações Unidas para a Eliminação da Discriminação Racial declarou em 1999 que "além da falta de serviços básicos, o habitar em campos implica não apenas uma segregação física para as comunidades rom, como também um isolamento político, econômico e cultural".

A luta política para conquistar o direito de autodefinir-se não é uma questão abstrata. Como evidenciado pela citação inicial, trata-se de um debate cujos efeitos são sentidos e vividos diariamente nos campos. Escreve Veronika Szente, numa reportagem de Roma Rights sobre a situação nos campos de Florença:
"Na Itália, a questão dos rom foi reduzida a uma questão de nômades. Isso significa que a pergunta feita pela população, pelas autoridades e por muitos dos ativistas ligados aos rom é: como lidar com pessoas socialmente inadaptadas à vida na sociedade moderna, ligadas por tradição a um estilo de vida itinerante?"

A teoria do "nômade", segundo o relatório do ERRC (European Roma Rights Center) sobre a Itália em 2000, "é freqüentemente utilizada como justificativa para excluir os rom das responsabilidades de decisão normalmente previstas para os demais seres humanos".

\section{"CAMPOS NÔMADES" E LEIS REGIONAIS}

"O campo não melhora a situação, nem a modifica. $O$ campo circunda e exclui seus hóspedes, até que as pessoas digam 'aqueles são verdadeiros rom, que não mudarão jamais'” (B. H., rom residente em Florença).

As etiquetas, as definições oficiais, expressam o que Michel Foucault denominou como regime de verdade. "A verdade - Foucault $(1988,13)$ escreve - é ligada por uma relação circular ao sistema de poder que a produz e sustenta, e aos efeitos que esta induz e que a reforçam". As etiquetas constituem, tanto para os etiquetados quanto para os que etiquetam, o espaço conceitual dentro do qual se colocam as possibilidades de cada um agir para transformar o existente. O poder de definir é um instrumento fundamental nas mãos do detentor de poder, para racionalizar e gerir aqueles percebidos como estranhos/estrangeiros/diferentes; ao mesmo tempo, as etiquetas traçam os limites dentro dos quais os etiquetados podem atuar no jogo político e construir suas demandas e suas possibilidades de promoção social. O sociólogo Liégeois $(1980,28)$ afirma a propósito que:

\footnotetext{
"A legislação, pelos efeitos que produz, contribui para alimentar $e$
} 
reforçar aqueles aspectos da imagem que lhe são indispensáveis [...]. A legislação faz o cigano viver na instabilidade, e este é depois qualificado como instável [...] o texto da lei se nutre da imagem. A imagem serve para racionalizá-lo e, por sua vez, também se alimenta de tal situação."

Entre os anos oitenta e noventa, dez dentre as vinte regiões italianas adotaram leis destinadas à "proteção dos ciganos" e de sua "cultura nômade". Cada lei define diversamente o seu objeto. Fala-se, por exemplo, de "nômade", "rom", "rom e sinti", "ciganos". Uma variedade de definições que é reconhecida porque, conforme sugere Marta $(1994,249)$, "o heterônimo constitui um elemento importante nas estratégias de intervenção das administrações públicas junto às populações ciganas". Visando atingir o objetivo pré-fixado, as leis regionais elencam uma série de instrumentos. $\mathrm{O}$ mais significativo dos mesmos são os campos (veja-se, por exemplo, a lei $32 / 90$ da Região Úmbria; a lei 11/88 da Região Friuli-Veneza Giulia; a lei 299/90 da Região Lombardia).

Mas como são definidos e identificados os destinatários das normas regionais? Fala-se em "minorias nômades" na Emilia Romagna, em "ciganos e nômades" na Ligúria, em "rom" no Vêneto, Lácio e Friuli-Veneza Giulia, em "rom e sinti" na Toscana, em "grupos tradicionalmente nômades e seminômades" na Lombardia, de "ciganos" na lei da província de Trento. Uma tal variedade de denominações, e mais as explicações oferecidas pelos etnólogos, dão uma idéia da dificuldade enfrentada pelo legislador ao tratar da matéria. Cai-se assim, por vezes, em definições quase tautológicas. A lei regional da Lombardia n. 299/89, por exemplo, no artigo 1 , parágrafo 3 , afirma: "para fins da presente lei, por nômades se entende aqueles pertencentes às etnias tradicionalmente nômades e seminômades".

Desse modo, a crença de que todos os rom e sinti sejam nômades e, portanto, desejosos de viver em campos, isolados da sociedade majoritária, termina ratificada e englobada na lei. O resultado dessa afirmação é que muitos rom são forçados por lei a viver em campos, realizando e ao mesmo tempo corroborando a imagem que deles têm os italianos.

Fica evidente, nas leis regionais, a ligação entre proteção do nomadismo e construção de campos. Os dois termos parecem ligados por uma relação de causa e efeito. Um aspecto que emerge dos textos normativos é o limitado conhecimento sobre os rom residentes no território, sobre as pessoas reais e suas necessidades; pelo contrário, ao centro do constructo e da lógica normativa está o mito do "cigano autêntico" e de como preservá-lo. Segundo Sibley (1995), "se os rom podem ser considerados exóticos e interessantes à distância, tornam-se sujeitos desviantes quando se movem no interno da sociedade majoritária". Por outro lado, conforme sugere Fonseca:

"quanto mais os ciganos parecem exóticos, mais 'genuínos' $e$, paradoxalmente, aceitáveis são considerados (na imaginação popular, senão no bar da aldeia). Vence quem melhor personifica o estereótipo" (Fonseca, 1995, 238).

$\mathrm{O}$ isolamento dos rom nos campos cumpre uma função central para a manutenção e reforço dos estereótipos. Privados da palavra e escondidos dos olhares dos verdadeiros cidadãos, existem somente como personificações dos estereótipos enraizados no imaginário coletivo. Faz-se necessária a pergunta: poderia a experiência direta romper este círculo de auto-referências?

Segundo Sibley $(1981,6)$ :

"Onde o sujeito minoriário entra em contato estreito com a sociedade majoritária, sobretudo nas cidades, a imagem romântica, o mito das culturas minoritárias, mantém-se como ponto de referência segundo o qual se baseia a avaliação da pessoa real. A experiência do contato direto pode contradizer o mito, mas nunca superálo. $O$ mito pode se manter porque a falência das expectativas míticas é atribuido ao desvio ou às patologias sociais resultantes do processo de urbanização."
Por tudo o dito acima, parece claro que a superação do "cigano mítico" é uma questão central inclusive para os que lidam com as políticas de habitação, e tal superação não se pode obter simplesmente retirando dos campos os rom. A segregação do campo rom, o seu caráter de gueto (Sigona, 2002), representa muito mais do que a falta da casa. O campo gera uma economia própria, uma sociedade, uma cultura. Faz-se portanto necessário responder a tal complexidade tanto com intervenções dirigidas, onde os rom sejam participantes ativos das políticas quanto, ao mesmo tempo, com a desconstrução na sociedade majoritária da imagem-esquema do "cigano" (Piasere, 2004). Posicionar no centro das políticas os rom e a sociedade majoritária, sobretudo os demais habitantes das periferias degradadas, é um modo de recordar a quem invoca e lamenta a morte do "cigano autêntico" que a maior parte dos campos são projetados, pensados e construídos pelos nossos arquitetos, agrimensores, engenheiros. Portanto, mais que habitat natural dos rom, são uma projeção arquitetônica de como a sociedade majoritária vê os "ciganos". Uma projeção de consequiências dramaticamente reais. O círculo vicioso que leva à construção de campos para milhares de rom sedentários, não apenas marca a sua vida cotidiana, mas igualmente define os limites dentro dos quais se guardam seus sonhos, expectativas e possibilidades de promoção social (Sigona, 2003).

\section{NÔMADE E/OU REFUGIADO}

Não obstante o crescente número de refugiados que chegam ao país, a Itália não definiu até agora seu papel como nação de asilo. A maioria destas pessoas tem duas vias possíveis a percorrer: transitar pelo país rumo a destinos de melhor acolhimento no norte da Europa; ou buscar o canal da lei de imigração, incluindo a esperança de, após um período de ilegalidade, ser regularizado em uma das anistias periódicas características da política imigratória 
italiana. Paradoxalmente, tentar a via do reconhecimento através da Convenção de Genebra, no caso de fluxos de massa, termina por ser uma das vias mais tortuosas para aqueles verdadeiramente necessitados de proteção (Hein, 2000, 139-161; Zetter et al, 2003). Este é o quadro geral onde se inscreve a resposta italiana ao caso da crise dos refugiados do Kosovo.

Os rom kosovares apareceram nas telas italianas somente ao término do bombardeamento da região pelas forças aliadas, não obstante um êxodo silencioso de meses. Apareceram quando, mesmo com a guerra oficialmente terminada, barcos carregados de pessoas continuavam a chegar à costa da Puglia. Os recémchegados levantaram muitas dúvidas na opinião pública. Estes refugiados de fato não se adaptavam bem ao discurso oficial da guerra. Dois eram os nós não resolvidos, os pontos que soavam particularmente dissonantes: se a guerra terminara, por que havia ainda gente que fugia do Kosovo? E como era possível que os bons albaneses, as vítimas por excelência, cumprissem agora o papel de carrascos? Alguns argumentavam que se tratava de refugiados disfarçados, pessoas querendo aproveitar da generosidade do país. "Fingem ser kosovares, mas são nômades!", dizem. "Como pode um nômade, um sem pátria, ser um refugiado, uma pessoa que escapa do próprio país?", acrescentavam. Eram os "nômades" arquitetando mais uma das suas. Misturavam-se aos pobres refugiados kosovares, imitavam o seu desespero e sofrimento para gozar das vantagens do acolhimento italiano.

Trata-se, no fundo, de velhos estereótipos. A questão é saber quais os impactos dos mesmos na definição de políticas e de práticas de intervenção sobre os rom.

A decisão do então ministro do Interior, de não estender a aplicabilidade das medidas de proteção temporária previstas no decreto do Primeiro Ministro (12 de maio de 1999) aos milhares de refugiados que chegavam às praias italianas após o fim dos bombardeios da OTAN, torna ainda mais procedente a dúvida expressa no parágrafo anterior.

Os protestos suscitados pela decisão do ministro permitiram que a situação se estabilizasse parcialmente, possibilitando a muitos rom acessar ao processo de asilo, nos casos de negativa da proteção temporária. Para quase todos, porém, a única forma de acolhimento real foram os "campos nômades" onde residiam parentes e amigos.

A presença de rom provenientes do Kosovo foi estimada em cerca de $10 \mathrm{mil}$ no ano de 1999. Segundo relatório da Comissão Européia contra o Racismo e a Intolerância (ECRI, 2002), os rom "comparativamente beneficiaram-se menos que outros grupos das diversas oportunidades de regularização". Muito freqüentemente, a única saída é a clandestinidade. Segundo dados recolhidos por Monasta (2001), em 2001, 2.936 dos cerca de 20 mil rom estrangeiros residentes em acampamentos legais e ilegais na Itália são provenientes do Kosovo.

\section{NÃO CIDADÃOS}

A definição do rom como "nômade" serve também para destacar um outro aspecto. A percepção dos rom como estrangeiros, como não italianos. Sob esta ótica podem ser lidas as práticas administrativas que delegam aos departamentos de "Estrangeiros e Nômades" questões inerentes a grupos rom e sinti de cidadania italiana (ver Turim, Roma). A esse respeito, afirma Piasere que

"A analogia nômadelcigano = estrangeiro é uma constante em nosso inconsciente coletivo, que as disposições oficiais continuam a confirmar, levando sempre à mesma equiparação: o nômade, como o estrangeiro, não deve gozar (ou não goza de fato) de todos os direitos de um cidadão" (Piasere, 1996, 26).

Trata-se de práticas enraizadas, manifestas em administrações tanto de direita quanto de esquerda. Como sublinha a pesquisa de Clough Marinaro sobre as políticas da administração de centroesquerda governada por Rutelli em Roma quanto à numerosa comunidade rom residente, não obstante as boas intenções iniciais, as políticas da prefeitura fundamse na premissa implícita de que os rom sejam "inerentemente nômades, desonestos e incapazes de viver numa sociedade moderna" (Clough Marinaro, 2003, 203204). Na prática, a "teoria dos nômades" é com frequiência utilizada para fornecer uma legitimação cultural à marginalização dos rom.

A tendência de negar as peculiaridades e diferenças internas à comunidade rom e sinti, "um mundo de mundos", como definido por Piasere (1999), é um elemento importante das políticas italianas. Seguemse dois corolários: assumir sua homogeneidade cultural e social e pretender a unanimidade quando se exprime suas necessidades e aspirações. Nas leis regionais, a negação das diferenças se manifesta também na falta de diferenciação entre sinti e rom de cidadania italiana ou não. Isso não ocorre na Ligúria e Lombardia (ver lei regional da Ligúria, 1992, artigo 1, parágrafo 2; lei regional da Lombardia 299/89, artigo 4, parágrafo 3), mas se trata de casos isolados. A falta de distinção entre estatutos jurídicos diferentes torna-se um obstáculo adicional para que as normas, definidas como "de tutela" dos rom, possam realmente exercer tal função.

Escreve Jean-Pierre Liégeois sobre a utilização instrumental, por parte do poder político, de elementos culturais, presumidos ou não, dos grupos "ciganos":

"O discurso político, [...] faz uso abundante de imagens estereotipadas, seja no modo de representar ciganos e viajantes nos textos de lei e nas regulamentações, seja nas definições introduzidas ao curso da ação política. [...] Por isso, ao longo dos anos, assiste-se a uma transformação das imagens em função do uso que delas feito e da evolução das instituições" (Liégeois, 1994, 156).

O "discurso público", o conjunto de definições públicas produzidas pela mídia (nacional e local), legitimadas por especialistas, cientistas ou testemunhas privilegiadas, assumidas como expressão da verdade e tornadas operativas no sistema político, determina o limite no qual se pode definir a cultura alheia, e seleciona os elementos que aparecem como mais funcionais ao próprio discurso (Dal Lago, 1998). 


\section{CONCLUSÕES}

"O cigano não é definido como é, mas sim como deve ser por necessidade de ordem sócio-política" (Liégeois,1980,9).

A crise do Kosovo, com a chegada à Itália de milhares de refugiados de etnia rom representa, no percurso aqui traçado, um momento chave. Um momento no qual se manifesta claramente o conflito entre os estereótipos consolidados associados aos "nômades" e as exigências de sobrevivência de ciganos em carne e osso fugidos da guerra. Conflito que encontrará uma acomodação nas práticas das pessoas envolvidas, mantendo porém sem mudança os estereótipos consolidados. Como se viu, de fato estes tendem a resistir ao confronto com a realidade, oferecendo uma chave de leitura para esta.

A breve análise do caso dos rom na Itália evidenciou também a circularidade da relação entre definições oficiais, políticas e práticas burocráticas, e o seu objeto. Conforme já dito, as definições oficiais, mais que descrever a realidade, a criam e modelam. Através da política dos "campos nômades", fundada sobre falsas premissas e escasso conhecimento das necessidades das pessoas reais destinatárias da intervenção, as administrações italianas criaram espaços de segregação que terminam nâo apenas por reforçar os estereótipos da sociedade majoritária, mas também por forçar, direta e indiretamente, os rom a viverem estes estereótipos. De "nômades" a nômades.

* Nando Sigona / Oxford Brokes University.

\section{NOTAS}

1- A tradução mais usual, para português, de rom é justamente " cigano ". Porém, os rom consideram o termo depreciativo, e como o artigo busca justamente criticar o estereótipo anti-rom, optou-se por não adotar a designação tida como insultuosa (nota do tradutor).

2 - Grupos de nômades da Europa Ocidental, considerados à parte dos rom, já que estes são em geral provenientes da Europa Oriental e dos Balcãs (n. do t.).

3- No original, em inglês, "politically correct" (n. do t.).

4 - No original italiano, "politetiche" (n. do t.).

\section{REFERÊNCIAS BIBLIOGRÁFICAS}

BRUNELLO, $\mathrm{P}$.

(1996) (ed.) L'urbanistica del disprezzo. Roma: manifesto libri.

\section{CERD}

(1999) Concluding Observations on Italy. Geneva: United Nations.

CLOUGHMARINARO, I.

(2003) 'Integration or marginalization? The failures of social policy for the Roma in Rome', Modern Italy, 8, 2 (2003): 203218.

DAL LAGO, A.

(1998) (a cura di) Lo straniero e il nemico, Milano: Costa \& Nolan.

ECRI

(2002) 2nd Report on Italy adopted the 22nd June 2001. Strasbourg: ECRI.

ERRC

(2000) Campland. Racial segregation of Roma in Italy. Budapest: ERRC.

FONSECA, I.

(1995) Bury me standing. The Gypsies and their journey. New York: Vintage Books.

FOUCAULT, $M$.

(1988) Foucault, M. (1988) Storia della sessualità: La volontà di sapere, vol. I, Milano: Feltrinelli (ed. orig. 1976).

HEIN, C.

(2000) "Italy: gateway to Europe, but not gatekeeper?" in Van Selm, J. Kosovo's refugees in the European Union, London: Pinter.

KARPATI, M.

(1969) 'La situazione attuale degli zingari in Italia', Lacio Drom, no.3-4-5: 77-83.

KARPATI, M. (a cura di)

(1993) Zingari ieri e oggi, Roma: edizioni Lacio Drom.

LIÉGEOIS, J.P.

(1980) 'Il discorso dell'ordine. Pubblici poteri e minoranze culturali', Lacio Drom, n.5: 9-29.

LIÉGEOIS, J.P.

(1994) Roma, Tsiganes, Voyageurs, Strasbourg: Council of Europe.

MARTA, C.

(1994) 'Zingari, Rom e nomadi: una minoranza di difficile definizione' in Vallini, C. (ed.) Minoranze e lingue minoritarie, Napoli: IUO.

MONASTA, L.

(2001) Note sulla mappatura degli insediamenti di Rom stranieri presenti in
Italia. Università di Firenze.

PIASERE, L.

(1991) Popoli delle Discariche. Saggi di antropologia zingari. Roma: CISU.

PIASERE, L.

(1995) (a cura di) Comunità zingare, comunità girovaghe, Napoli: Liguori.

PIASERE, L.

(1996) "Stranieri e nomadi" in P. Brunello (a cura di) (1996), pp.23-28.

PIASERE, L.

(1999) Un Mondo di Mondi. Antropologia delle culture rom. Napoli: l'ancora.

PIASERE, L.

(2004) I rom d'Europa. Una storia moderna. Bari, Roma: Laterza.

SCHIAVONE, G.

(1997) 'I Rom rifugiati' in Osella C. (ed) Zingari profughi, il popolo invisibile. Torino: edizioni Gruppo Abele.

SIBLEY, D.

(1981) Outsiders in Urban Societies. Oxford: Blackwell.

SIBLEY, D.

(1995) Geographies of Exclusion. London and New York: Routledge.

SIDOTI, S.

(2002) Pratiche d'erranza quotidiana in una comunità di Caminanti siciliani, Progetto OPRE ROMA: The Education of Gypsy Childhood in Europe.

SIGONA, N.

(2002) Figli del Ghetto. Gli italiani, i campi nomadi e l'invenzione degli zingari. Trento: Nonluoghi.

SIGONA, N.

(2003) 'How can a 'nomad' be a 'refugee'? Kosovo Roma and Labelling Policy in Italy', Sociology, 37 (1): 69-79.

SORAVIA, G

1981, 'Zingari in Sicilia', Lacio Drom, n.2: 31-33.

SZENTE, V.L.

(1997) "Field Report: Italy", Roma Rights, autunno '97, pp.51-53.

VIAGGIO, G.

(1997) Storia degli Zingari in Italia. Roma: Anicia.

ZETTER, R.

(1991) "Labelling refugees: Forming and transforming a bureaucratic identity". Journal of Refugee Studies, 4(1): 39-61.

ZETTER, R.; GRIFFITHS, D. EN. SIGONA (2002) Survey of Policy and Practice of Refugee Integration in the EU. Oxford: OBU (rapporto di ricerca). 